Canadian Journal of Fisheries and Aquatic Sciences

Canadian Science Publishing

Journal canadien des sciences halieutiques et aquatiques

\title{
FLEXSELECT: counter-herding device to reduce bycatch in crustacean trawl fisheries
}

\begin{tabular}{|c|c|}
\hline Journal: & Canadian Journal of Fisheries and Aquatic Sciences \\
\hline Manuscript ID & cjfas-2017-0226.R2 \\
\hline Manuscript Type: & Article \\
\hline Date Submitted by the Author: & 28-Jul-2017 \\
\hline Complete List of Authors: & $\begin{array}{l}\text { Melli, Valentina; Danmarks Tekniske Universitet Institut for Akvatiske } \\
\text { Ressourcer, Ecosystem based Marine Management } \\
\text { Karlsen, Junita; DTU, DTU Aqua } \\
\text { Feekings, Jordan; Technical University of Denmark, National Institute of } \\
\text { Aquatic Resources } \\
\text { Herrmann, Bent; SINTEF Fisheries and Aquaculture, Fishing Gear } \\
\text { Technology } \\
\text { Krag, Ludvig; Technical University of Denmark, }\end{array}$ \\
\hline $\begin{array}{r}\text { Is the invited manuscript for } \\
\text { consideration in a Special } \\
\text { Issue? : }\end{array}$ & N/A \\
\hline Keyword: & $\begin{array}{l}\text { Bycatch reduction, Nephrops, scaring lines, catch comparison, trawl } \\
\text { selectivity }\end{array}$ \\
\hline
\end{tabular}




\section{fisheries}

$5{ }^{1}$ DTU Aqua, National Institute of Aquatic Resources, North Sea Science Park, DK-9850, Hirtshals,

6 Denmark

$7 \quad{ }^{2}$ SINTEF Fisheries and Aquaculture, Willemoesvej 2, DK-9850 Hirtshals, Denmark

$8 \quad{ }^{3}$ University of Troms $\emptyset$, Breivika, N-9037 Tromsø, Norway

9

10 Email addresses: VM - vmel@aqua.dtu.dk; JDK - juka@aqua.dtu.dk; JPF - jpfe@aqua.dtu.dk; BH -

11 Bent.Herrmann@sintef.no; LAK-lak@aqua.dtu.dk

12

13 Correspondence: Valentina Melli, DTU Aqua, National Institute of Aquatic Resources, North Sea Science

14 Park, DK-9850, Hirtshals, Denmark.

15 Telephone: +45 35883270; e-mail: vmel@aqua.dtu.dk

16

17

18

19

20

21

22

23

24 
25 Abstract

26 FLEXSELECT is a simple counter-herding device which aims at reducing the bycatch of fish by

27 scaring them away from the trawl path without affecting the catches of the target species.

28

29

30

31

32

33

34

35

36

37

FLEXSELECT was tested in the Norway lobster (Nephrops norvegicus) directed trawl fishery, as this includes bycatch of both roundfish and flatfish. Length-based data were collected for Nephrops, four roundfish species (cod, haddock, whiting and hake) and two flatfish species (plaice and lemon sole) and length-based catch comparisons performed. No significant effect on the target species, Nephrops, was detected, whereas a reduction of $39 \%$ (Cl: $29-46 \%$ ) was obtained for the overall number of fish. Catches of all the six fish species examined were significantly reduced by FLEXSELECT, with the efficiency varying considerably among species and over length classes. No significant diel differences were found for either roundfish or flatfish species. FLEXSELECT prevents bycatch species from interacting with the trawl, thus most likely enhancing their survival and fitness. Moreover, its fast attachment system makes FLEXSELECT a flexible tool, adaptable to different fisheries and catch goals.

\section{Keywords}

Bycatch reduction, Nephrops, scaring lines, catch comparison, trawl selectivity 
Introduction

47 The capture and subsequent discarding of unwanted species and sizes is recognized as damaging to both fisheries and marine conservation objectives (Kelleher 2005). Therefore,

49 fishermen are faced with the challenge of improving the species and size selectivity of their

50 fishing gears. Globally, considerable effort has been taken to reduce discards through both

51 technical and managerial measures. Within Europe, the latest measure has been the landing

52 obligation (discard ban) introduced as part of the reformed European Union Common Fisheries

53 Policy (European Commission 2013). The landing obligation, directed at all quota regulated

54 species, introduces a strong incentive for the fishing industry to reduce unwanted catches since

55 these are now counted towards quotas. Additionally, the loss of space on board and the

56 increased handling costs of this less valuable fraction of the catch may further incentivise

57 fishermen to be more selective. Nonetheless, fishing typically involves high variability in catch

58 compositions, thus increasing the challenge to reduce unwanted bycatch. Highly flexible

59 devices, which are easy to attach to and remove from the gear, are needed to adapt the

60 selectivity of fishing gears to haul-by-haul variations observed in catch compositions.

61 Many devices have already been successful in reducing bycatch (Kelleher 2005). They typically

62 exploit interspecific differences in terms of morphology and behaviour to improve selectivity

63 inside and in front of the trawl (Glass 2000; Catchpole and Gray 2010). Examples which have 64 improved selectivity inside the trawl include increased mesh sizes (e.g. Beutel et al. 2008;

65 Frandsen et al. 2011), grids (Graham and Fryer 2006; Grimaldo et al. 2008), square mesh panels

66 (e.g. Krag et al. 2008; Lomeli and Wakefield 2013), and species segregation into different 67 compartments (e.g. Holst et al. 2009; Krag et al. 2009). Devices aiming at improving selectivity 
68 in front of the trawl typically do so by preventing certain species from entering the gear. For example, a raised footrope can reduce the catch of flatfish and juveniles of demersal fish (Hannah and Jones 2001; Krag et al. 2010); a topless gear allows the escape of roundfish species over the headline (He et al. 2007; Krag et al. 2015); and a modification of the sweeps interferes with the herding of fish towards the net mouth (Rose et al. 2010; Sistiaga et al. 2015). These devices have the advantage of minimizing fish interaction with the gear since they address the initial stimuli that cause fish capture in the first place. Therefore, they likely enhance species survival and fitness (Chopin and Arimoto 1995).

During fishing, the doors and sweeps of the trawl are the first parts of the gear that interact with the fish. These components determine the overall geometry of the trawl, as the doors spread the gear and the sweeps connect the doors to the trawl. However, doors and sweeps also herd fish into the path of the trawl by exploiting their natural anti-predator behaviour (Glass and Wardle 1989; Engås and Ona 1990; Winger et al. 2010). The herding process starts with an anti-predator reaction triggered by the approaching trawl. The doors and sweeps produce vibrations and a sand cloud, thus stimulating fish's avoidance behaviour. Their reactions are often considered to be mainly vision-dependent, as herding has been observed to cease at low light levels (Wardle 1993; Kim and Wardle 1998); however other stimuli associate to trawling (e.g. sound) may enable herding at lower light levels (Engås and Ona 1990). The type of reaction is then determined by species-specific anti-predator strategies. Flatfish, specialized in camouflage, are reticent to flee until the predator is very close (Ryer 2008). When they flee, it is to keep a safe distance from the predator and resettle on the seafloor to hide. On the contrary, roundfish tend to respond at greater distances, swimming away 
90 (Noettestad and Axelsen 1999; He 2011). Despite these differences, all individuals in the area

91 between the doors that flee are herded towards the trawl mouth. Nonetheless, for herding to

92 be effective, fish must have sufficient time and endurance to reach the trawl mouth (Winger et

93 al. 2010). Thus, it is a fish's swimming capacity that determines its herding potential. If a fish's

94 endurance is lower than the time required to cover the distance to the trawl mouth, it is

95 overrun by the sweeps and escapes capture (e.g., Mathai et al. 1984; Winger et al. 2004;

96 Sistiaga et al. 2015). Swimming performances are known to vary among species and sizes, to

97 depend on individual fitness, and to be influenced by environmental parameters like 98 temperature (Winger et al. 2010).

99 Ryer (2008) hypothesized that herding of roundfish in a flatfish-directed trawl fishery could be 100 reduced with a counter-herding design, e.g. a second inverted stimulus, positioned between 101 the sweeps. However, Ryer (2008) also highlighted how the implementation of such a counter102 herding device would entail significant engineering challenges. For example, different tensions 103 were expected on the components of the device when the spread of the trawl doors changes 104 according to bottom topography and sediment characteristics. For this reason, no scientific test 105 of a counter-herding design has, to our knowledge, been performed until now.

106 This study aimed to design and test the efficiency of a counter-herding device, FLEXSELECT, in 107 reducing fish bycatch. We tested FLEXSELECT in the mixed trawl fishery targeting Norway 108 lobster (Nephrops norvegicus), hereafter referred to as Nephrops. This fishery has a significant 109 bycatch of both roundfish and flatfish. The fish bycatch involves economically important 110 species but is usually of low quality due to its interaction with the crustaceans during the 
111 catching process (Karlsen et al. 2015) and can potentially choke the fishery once fish quotas are

112 exhausted. In the frame of the landing obligation, fishermen need to reduce the fish fraction to 113 be able to fully utilise Nephrops quotas. Furthermore, the small mesh sizes used lead to 114 substantial quantities of undersized roundfish and flatfish being caught, thus leading to high 115 proportions discarded (Kelleher 2005). Therefore, this fishery represents the perfect case study 116 to investigate a counter-herding device. If effective, the advantages of FLEXSELECT are: i) a

117 reduction of fish bycatch; ii) a reduction in the interaction of potential bycatch with the net, 118 thus most likely enhancing its survival and fitness chances; and iii) the adaptation of the gear's 119 selectivity to obtain the desired catch composition on a haul-by-haul basis. The efficiency of 120 FLEXSELECT is expected to differ among species and sizes, thus the results concerning all 121 relevant commercial species were examined length-based and discussed in relation to the 122 different behavioural anti-predator strategies.

\section{Materials and methods}

\section{FLEXSELECT design}

125 The FLEXSELECT device consisted of four lines connected to a central metal ring (25 mm thick, $12617 \mathrm{~cm}$ diameter, $3 \mathrm{~kg}$ ), located at approximately $20 \mathrm{~m}$ ahead of the trawl mouth (Fig. 1). The 127 two positioning lines $(54 \mathrm{~m}$ ) were made of mix wires (steel core and polypropylene cover, 6 128 strands, $14 \mathrm{~mm}$ in diameter, $0.21 \mathrm{~kg} / \mathrm{m}$ ). Two floats (115 g buoyancy) were attached at 2 and 5 $129 \mathrm{~m}$ from the door/clump to prevent the long wires from twisting around the sweeps during the 130 net deployment. The desired counter-herding effect was addressed with the two scaring lines

$131(23.6 \mathrm{~m})$ attached in front of the bridles. They consisted of thick ropes (polypropylene, 3 
132 strands, $26 \mathrm{~mm}$ in diameter, $0.31 \mathrm{~kg} / \mathrm{m})$, meant to sweep the sea bottom and generate a sand 133 cloud. Viking links and hammer locks ( $1.5 \mathrm{t} \mathrm{lift,} 0.7 \mathrm{~kg}$ ), as well as swivels, were used to connect 134 the FLEXSELECT lines to the gear components and to the central ring. These facilitated efficient 135 coupling and decoupling of the FLEXSELECT lines to the gear. The challenge in designing 136 FLEXSELECT was to make an efficient counter-herding stimulus without preventing the trawl 137 from obtaining its intended geometry. It can be expected that heavier ropes would improve 138 the herding efficiency as the interaction with the seafloor and sand cloud would be greater. 139 However, a heavier device also increases the operational difficulties in terms of obtaining an 140 optimal spread of the gear. Therefore, relative light materials were chosen.

\section{Sea Trial}

142 The experimental trial was conducted on board the research vessel "Havfisken" (17 m, 373 $143 \mathrm{~kW}$ ), during 5-20 September 2016. The vessel was equipped for three-wire, twin-trawling, with 144 two identical Combi trawls (40 m long footrope, 420 meshes circumference) towed in parallel. 145 The two trawls were equipped with identical $40 \mathrm{~mm}$ square mesh codends to retain the entire 146 population encountered. Actual mesh sizes were measured on dry netting (41.65 \pm 1.33$)$. Each 147 codend was horizontally divided into two compartments due to a second experiment not 148 included in the present study.

FLEXSELECT was mounted on one trawl while the other worked as a control. This setting 150 assured that both trawls encountered similar species compositions and abundances over time. 151 To prevent any systematic effect of the trawl position (side of the vessel) on the catch, the 152 FLEXSELECT device was shifted from one trawl to the other approximately every sixth haul. The 
153 distance between the inner wingtip of the two trawls, about $50 \mathrm{~m}$, was assumed sufficient to 154 prevent overestimation of the control catch due to fish escaping from the FLEXSELECT device. 155 The twin rig was spread with two Type 2 Thyborøn doors $\left(1.78 \mathrm{~m}^{2}, 197 \mathrm{~kg}\right)$, with an additional 156 weight of $25 \mathrm{~kg}$ to obtain a better spreading force, and a $400 \mathrm{~kg}$ triangular central clump. The 157 trawls were rigged with $75 \mathrm{~m}$ long single wire sweeps with $4.3 \mathrm{~cm}$ (diameter) rubber cookies. 158 The trawl doors and clump were equipped with distance sensors (Simrad PI), which 159 continuously provided information about the spread of the two trawls during towing. Since 160 only one trawl was equipped with the counter-herding device and thus potentially limited in its 161 spread, the two values were constantly monitored during towing.

162 Fishing was conducted in commercial grounds in the Skagerrak Sea, at depths between $33 \mathrm{~m}$ 163 and $87 \mathrm{~m}$. To investigate the diel effects, hauls were performed during day- and night-time, 164 avoiding one hour before and after sunrise and sunset. The total catch was weighed and sorted 165 by species. The total length of all commercial fish species and the carapace length of Nephrops 166 were measured and rounded down to the nearest centimetre and millimetre, respectively.

\section{Statistical analyses}

168 The only difference between the two trawls was the attachment of FLEXSELECT to one of them.

169 Therefore, any difference in the catch between the two trawls was assumed to be caused by 170 FLEXSELECT presence. Its effect was assessed for each species separately, comparing the 171 catches of the test trawl (T) and the control trawl (C) while accounting for potential length 172 dependencies. Count data for the different length groups of each species were used to 173 estimate the curvature of a model for the size-dependent catch comparison rate $c c(I)$ with $95 \%$ 
174 Efron confidence intervals (Efron 1982). The confidence intervals were based on double 175 bootstrapping (1000 repetitions), accounting for uncertainty due to within- and between-haul 176 variation in the catching process. For each species, only hauls with 10 or more individuals were 177 included in the analysis following Krag et al. (2014). Separate analyses were conducted for day178 and night-time hauls to enable inferring potential diel differences in the efficiency of the 179 FLEXSELECT device. We adapted the catch comparison analysis methodology based on paired 180 catch data described by Krag et al. (2015) while adopting recent improvements in model 181 average estimation described by Herrmann et al. (2017). The analyses were performed using 182 the software SELNET (Herrmann et al. 2012). The statistical procedure is described step-by-step 183 in Appendix 1.

184 The baseline for no effect on the catch comparison rate is a value of 0.5 for paired catch 185 comparison data (Krag et al. 2014). However, this assumed that the two trawls fished an area 186 of similar size. We considered that, according to the proportions of the trawls used in this 187 study, a difference in spread between the two trawls higher than $4 \mathrm{~m}$ could have consequences 188 on the overall geometry of the trawls. Therefore, those hauls were excluded from the analyses. 189 For smaller differences we calculated a bias-corrected baseline $c c_{0}$ that accounted for little 190 changes in the towed area:

191

$$
c c_{0}=\frac{\sum_{j=1}^{h} S T_{j}}{\sum_{j=1}^{h}\left(S T_{j}+S C_{j}\right)}
$$

192 where STj and SCj are the averaged door-to-clump distances for the test and control trawls in 193 haul $j$, respectively. 
194 Catch ratios (cr) and 95\% Efron confidence intervals were calculated to directly quantify the 195 differences in catch between the test and control trawls. Catch ratios were obtained using the 196 relationship between $c r$ and cc (Herrmann et al. 2017):

$197(2)$

$$
\operatorname{cr}(l)=\frac{c c(l)}{1-c c(l)}
$$

198 A value of 1.0 for $\mathrm{cr}(I)$ indicates that there is no difference in catch between the two trawls, 199 meaning that, for a given species and length, FLEXSELECT would have failed to modify the 200 catch. However, similarly to the baseline value for the $c c(I)$, a bias-corrected baseline $c r_{0}$ equal 201 to 0.98 was calculated applying Equation 1 and 2.

202 Finally, to provide length-averaged values for the effect of FLEXSELECT on the species 203 examined, we calculated the average catch ratio ( $\left.c r_{\text {average }}\right)$ by summing all individuals caught 204 per trawl in each haul (Herrmann et al. 2017). However, since the effect was not constant 205 throughout length classes, it is important to notice that $\mathrm{cr}_{\text {average }}$ values are specific for the 206 population structure encountered during the experimental trial. Therefore, these values 207 cannot be extrapolated to other scenarios in which the size structure of the fish population 208 may be different.

\section{Results}

210 During the sea trial, 30 hauls were conducted, of which 26 were valid and included in the

211 statistical analyses (Table 1). Four hauls were excluded due to initial technical problems related

212 to the gears spread, with the test trawl spreading significantly less than the control. This 213 difference was probably caused by a partial twisting of the positioning lines around the sweeps 
214 and it was solved through the addition of floats to the positioning lines (see FLEXSELECT

215 design). Of the 26 valid hauls, eight were carried out at night and 18 during daylight hours. The

216 towing time varied from 30 to $135 \mathrm{~min}$, and the depth from 33 to $87 \mathrm{~m}$. The total catches of the

217 control trawl varied between 90.5 and $1539 \mathrm{~kg}$, while the catches in the experimental trawl

218 ranged from 55 to $1145 \mathrm{~kg}$. The mean difference in spread between the trawls was used to

219 account for small differences in swept area by calculating a corrected baseline for no effect on

220 the catch comparison rates and catch ratios. Trawl-spread values were not available for two

221 hauls (25 and 26) due to a malfunctioning of the sensor on the central clump. However, the

222 door spread was consistent with those obtained at similar depths thus the hauls were not

223 excluded from the analyses.

224 Seven commercial species were included in the analysis: the target species, Nephrops; four 225 roundfish species, cod (Gadus morhua), haddock (Melanogrammus aeglefinus), whiting 226 (Merlangius merlangus) and hake (Merluccius merluccius); and two flatfish species, plaice 227 (Pleuronectes platessa) and lemon sole (Microstomus kitt). All species were sampled in both 228 night- and day-time except for Nephrops, whose presence outside of their burrows was limited 229 to day-time, and hake, which in general was caught in few numbers (less than 10 individuals 230 per haul) during night-time (Table 2). Due to the intense activity of the Nephrops-directed 231 fishery in the period of the study, very few fish were encountered while fishing in the closest 232 Nephrops grounds. Consequently, some of the hauls were conducted in proximity to the 233 Nephrops grounds but in deeper water, where higher abundances of fish were expected.

234 Target species: Nephrops 
235 The catch comparison curve for Nephrops described well the experimental data for length 236 classes $25-55 \mathrm{~cm}$ (Fig. 2). For the lengths where fewer individuals were caught, the catch 237 comparison rates were subject to increasing binominal noise, as shown by the increasing size 238 of the confidence intervals. The ability of the catch comparison curves to describe the 239 experimental data is also demonstrated by the fit statistics (Table 3). The $p$-value for Nephrops 240 is $>0.05$, meaning that the model can be trusted to represent the experimental data (see

241 Appendix 1). The catch ratio between the test and the control trawls did not detect any 242 significant effect of FLEXSELECT on the target species, as the confidence intervals overlapped 243 the baseline in all the length classes (Fig. 2).

\section{Fish species}

245 For the six fish species examined, FLEXSELECT reduced the catch in numbers by 39\% (Cl: 29246 46\%). When considering the Minimum Conservation Reference Sizes (MCRS, previously 247 Minimum Landing Sizes), catches of individuals above and below the limit were reduced by 248 49\% (Cl: 39-57\%) and 29\% (Cl: 19-39\%), respectively (Table 4). The catch ratio averaged over 249 length showed significant effects for all fish species except for cod (Table 4). This could possibly 250 be due to the high number of small cod caught during the trial. The reduction in catch was 251 strongest for lemon sole (65\%), followed by hake (63\%), haddock (57\%) and whiting (46\%).

252 However, these reductions in catch are specific for the population structure encountered 253 during the experiment and cannot be generalized. In particular, the roundfish examined 254 present length-based differences in their response to FLEXSELECT, thus the averaged rates 255 depend on the length classes most abundant in the data. 
256 Roundfish

257 The catch comparison curves for all the four roundfish species analysed described the main

258 trends in the data relatively well, without systematic deviations between the experimental

259 points and the modelled curves (Fig. 3). For cod, haddock and whiting, the model fits provided

$260 p$-values $<0.05$ (Table 3), indicating potential problems with the model in describing the

261 experimental data (see Appendix 1). However, considering that no structure was detected in

262 the deviations between the data and the modelled catch comparison curves for any of the

263 species, the low p-values may be due to overdispersion in the data. Therefore, we were

264 confident in applying the model to describe the catch comparison rates also for these species.

265 A significant catch reduction was detected for at least some of the length classes of all the four

266 roundfish species analysed (Fig. 3). Haddock and whiting showed the largest response and a

267 strong length-dependent effect, with larger individuals escaping from the experimental trawl in

268 higher numbers than smaller individuals. The effect on cod was significant for individuals

269 between $25 \mathrm{~cm}$ and $71 \mathrm{~cm}$, as the catch ratio was significantly lower than 0.98 . On the

270 contrary, small individuals (below $14 \mathrm{~cm}$ ) were more effectively caught by the test trawl. Hake,

271 despite the small amount of individuals sampled, showed a strong response to the FLEXSELECT

272 device for all the length classes represented.

273 Flatfish

274 Similarly, the catch comparison curves for the two flatfish species analysed described the main

275 trends in the data relatively well (Fig. 4). $p$-values for both species were above 0.5 , indicating a 276 good model representation of the data. The catch ratio curves show that lemon sole catches 
277 were significantly reduced for length classes which were well represented in the data, whereas

278 only small plaice (below $35 \mathrm{~cm}$ ) were significantly affected by FLEXSELECT (Fig. 4).

\section{Day- and night-time comparison}

280 Potential differences in catch efficiency between night- and day-time were investigated by 281 overlapping the respective confidence intervals (Fig. 5). A lower number of night-time hauls 282 compared to day-time hauls were performed, thus the number of individuals is generally lower 283 in the night-time analyses. In particular, the amount of data for lemon sole during night-time 284 was small $(n=45)$ and the dispersion so high that the resulting $p$-value was lower than 0.05 285 (Table 3). Despite this, all the model fits seem to represent the experimental points well, and 286 no systematic pattern was observed in the residuals. No significant differences between day287 and night-time were found for any of the species examined, as the confidence intervals 288 overlapped for all the length classes represented. An exception was observed for haddock, 289 where the two confidence intervals did not overlap for one length class $(17 \mathrm{~cm})$.

\section{Discussion}

291 This study showed that the bycatch of fish species can be substantially reduced by FLEXSELECT 292 without affecting the catch of the target species Nephrops. The device was effective on all the 293 six fish species analysed, with the intensity of the effect varying across species and length 294 classes. FLEXSELECT reduced the overall number of fish by $39 \%$ (Cl: $29-46 \%)$, a percentage that 295 increases to $49 \%$ ( $\mathrm{Cl}: 39-57 \%)$ when considering only individuals above MCRS due to the 296 length-dependency of the effect. Although the individuals above MCRS have a higher economic 297 value, a reduction of bigger and thus heavier individuals enhances higher quota savings. 
298 Therefore, this result is consistent with FLEXSELECT application to the Nephrops-directed mix 299 trawl fishery, in which a reduction of fish bycatch is desirable after exhaustion of fish quotas. In 300 such periods, fish in general represents an unwanted bycatch. Moreover, FLEXSELECT could be 301 combined with traditional selective devices (e.g. square mesh panels), which are efficient in 302 releasing juveniles, to achieve a larger overall reduction of bycatch. Furthermore, a proportion 303 of the small individuals captured during the trial were retained due to the small mesh size used 304 in the codend (40 mm square mesh). These individuals would typically escape the standard 305 commercial fishing gears used in Nephrops-directed fisheries (80-90 mm diamond mesh), 306 although after potentially damaging interactions with the trawl.

307 The effects of FLEXSELECT were diverse, both between and within the groups of roundfish and 308 flatfish. As expected, roundfish were effectively stimulated and escaped capture from the trawl 309 with the counter-herding device. In fact, we designed FLEXSELECT following the same principle 310 of stimuli which causes herding and makes trawls efficient gears. Gadoids which can be 311 encountered in high densities, like whiting and haddock, were previously described forming 312 shoals that facilitate an ordered herding behaviour (Jones et al. 2008); similarly, they were 313 efficiently counter-herded by FLEXSELECT. Their catches were reduced on average by $46 \%$ and $31457 \%$, respectively. The strong length-dependency evident for both species is likely related to 315 different swimming performances across length classes, with bigger individuals being able to 316 sustain higher speeds for longer periods (He 1993). A plausible explanation is that bigger 317 individuals were led away from the trawl path by FLEXSELECT scaring lines, whereas smaller 318 individuals followed a different escape strategy or were overrun, remaining in the trawl path. 
319 A similar effect also emerged between cod and hake, although varying in the strength of the 320 response. The response of hake to FLEXSELECT's scaring lines was strong for most of the length 321 classes encountered $(21-77 \mathrm{~cm})$, despite the low number of individuals. Cod also showed a 322 response to FLEXSELECT for a similar range of classes $(25-71 \mathrm{~cm})$ however the effect was 323 smaller and more variable. We compared this result with other modifications introduced in the 324 trawl mouth area to determine if a higher reduction of cod catches can be achieved. Krag et al. 325 (2015) obtained a significant reduction in cod catches for individuals bigger than $35 \mathrm{~cm}$ using a 326 topless trawl, but this was strongly affected by the height of the headline and thus not 327 applicable to every trawl. A higher reduction was achieved by raising the footrope (Krag et al. 328 2010), as cod in general tend to stay close to the seafloor. Unfortunately, this solution is not 329 applicable in a crustacean fishery without affecting the catches of the target species. 330 Furthermore, small cod $(<14 \mathrm{~cm})$ were caught in significantly higher numbers in the trawl with 331 FLEXSELECT. Juvenile cod are known to stay closer to the seafloor than adult cod, and are often 332 observed to escape below the fishing line after coming in contact with it (Winger et al. 2010). 333 Thus, it is possible that these individuals came in contact with the FLEXSELECT lines and were 334 subsequently exposed to capture by the trawl. In commercial gears, this result does not 335 represent a major concern, as juveniles of these sizes would not be caught by the range of 336 mesh sizes used in Nephrops directed fisheries. On the contrary, an adaptation of FLEXSELECT 337 may be used in scientific surveys to sample small length classes, usually underestimated due to 338 this difference in catchability (Harley and Myers 2001).

339 Different effects were also detected between the two flatfish species examined. Flatfish antipredator strategy is based on camouflage, and normally their swimming capacities are limited 
341 (Ryer et al. 2008). However, little is known about inter-specific differences, and previous 342 studies have focused on a limited number of species. In our experiment, lemon sole was the 343 most affected species, with a reduction of $65 \%$ (in numbers). On the contrary, plaice was 344 affected only for individuals smaller than $35 \mathrm{~cm}$, and only a slight reduction in catches was 345 obtained. A first potential explanation may be a size-dependent behaviour caused by 346 swimming capacity constraints. Winger et al. (2004) observed that the escape strategy of small 347 plaice $(<30 \mathrm{~cm})$ consists mainly of fast swimming bursts alternated with resting periods, while 348 larger individuals (greater than or equal to $30 \mathrm{~cm}$ ) prefer continuous swimming. Thus, as most 349 lemon soles captured in this study were of $20-30 \mathrm{~cm}$, a swimming strategy similar to small 350 plaice seems likely. Nonetheless, the effect of FLEXSELECT on lemon sole was considerably 351 higher than the effect on small plaice, suggesting additional differences between the species. 352 The degree of burial, for example, may be an important factor in determining reactivity and the 353 timing of the first response. More studies are necessary to enlighten species-specific 354 behaviours in flatfish and their potential applicability to bycatch reduction devices. For 355 example, our results suggest that plaice is only slightly affected by the counter-herding device, 356 thus fisheries that target specifically this species may use FLEXSELECT to reduce the bycatch of 357 roundfish.

358 No diel differences were observed in FLEXSELECT's effect, despite several studies having 359 demonstrated that both roundfish (Walsh and Hickey 1993) and flatfish (Ryer and Barnett, 360 2006) do not respond with an ordinated herding when the light level is below species visual 361 perception thresholds. Nevertheless, a lack of diel variation in FLEXSELECT's efficiency is 
362 desirable, as Nephrops fisheries typically take place under different light levels, depending on 363 the season and the area (Feekings et al. 2015).

364 On the basis of the results obtained, we conclude that FLEXSELECT represents an effective 365 bycatch reduction measure, potentially adaptable to different fisheries. Contrary to most other 366 selective devices, FLEXSELECT can be used on a haul-by-haul level, deciding its use on the basis 367 of the catch composition. This flexibility allows both an occasional and a more permanent use.

368 For example, FLEXSELECT can be used in specific periods or areas to avoid catching fish during 369 the spawning seasons, to reduce catches when prices are low, or as an alternative to 370 temporary area closures (Dunn et al. 2011). Moreover, the device can be deployed on a more 371 permanent base to reduce fish catches in those fisheries in which these represent an 372 undesirable catch. Among these, shrimp trawl fisheries could benefit from using FLEXSELECT, 373 after its adaptation to the gear geometry, as it may not only reduce fish bycatch but also 374 minimize its interaction with the net and the rest of the catch. Indeed, this "preventive" 375 approach has recently gained interest to address bycatch in these fisheries (McHugh et al. 376 2017). Therefore, the applicability of FLEXSELECT is much wider than the Nephrops-directed 377 mixed trawl fishery presented here and should be tested in other fisheries as well. Moreover, 378 we believe the efficacy of FLEXSELECT could be optimized by modifying the intensity of the 379 stimulus it produces, for example by using heavier components or by increasing their visibility. 380 Nonetheless, before modifications can be introduced in the design, the mechanism through 381 which FLEXSELECT works needs to be better understood. It is unclear from the results of this 382 study if FLEXSELECT's scaring lines stimulate fish to rise vertically in the water column and escape over the headline, or if they deviate their path to the wing tips. In the latter case, 
384 FLEXSELECT's effect could be increased by changing the position of the central ring, thus 385 altering the angles created by the lines. The angle respect to the towing direction is indeed 386 recognized as an important factor in determining herding (Winger et al. 2010) and thus, we 387 expect also for counter-herding. Further studies are necessary to identify which species can be 388 prevented from entering the trawl and which are more effectively released later inside the 389 trawl. This study focused on the main commercial species in the case study fishery, as they are 390 included in the landing obligation and thus represent a priority for the fishermen. However, 391 FLEXSELECT's effect likely extends to other species which are commercially less relevant but 392 may still be important in an ecosystem context.

\section{Acknowledgements}

394 This study has received funding from the European Maritime and Fisheries Fund 395 (https://ec.europa.eu/fisheries/cfp/emff en) and the Ministry of Environment and Food of 396 Denmark. Projects: FlexSelect - Scaring lines, an innovative and flexible solution for the 397 Nephrops fishery (Grant Agreement No 33113-I-16-068) and Vision - Development of an 398 optimal and flexible selective system for trawl by use of new technology and underexploited 399 fish behaviour (Grant Agreement No 33113-I-16-015)

\section{References}

401 Beutel, D., Skrobe, L., Castro, K., Ruhle, P., O'Grady, J., and Knight, J. 2008. Bycatch reduction in the 402 Northeast USA directed haddock bottom trawl fishery. Fish. Res. 94(2), 190-198. 403 doi:10.1016/j.fishres.2008.08.008 
404 Catchpole, T.L., and Gray, T.S. 2010. Reducing discards of fish at sea: a review of European pilot 405 projects. J. Environ. Manage. 91(3), 717-723. doi:10.1016/j.jenvman.2009.09.035

406 Efron, B. 1982. The jackknife, the bootstrap and other resampling plans. Society for industrial and 407 applied mathematics (SIAM) Monograph No. 38, CBSM-NSF.

408 Engås, A., and Ona, E. 1990. Day and night fish distribution pattern in the net mouth area of the 409 Norwegian bottom-sampling trawl. ICES report 189, 123-127.

410 Chopin, F.S., and Arimoto, T. 1995. The condition of fish escaping from fishing gears-a review. Fish.

411 Res. 21(3-4), 315-327. doi:10.1016/0165-7836(94)00301-C

412 Dunn, D.C., Boustany, A.M., and Halpin, P.N. 2011. Spatio-temporal management of fisheries to reduce 413 by-catch and increase fishing selectivity. Fish Fish. 12(1), 110-119. doi:10.1111/j.1467$414 \quad 2979.2010 .00388 . x$

415 European Union 2013. Regulation (EU) No 1380/2013 of the European Parliament and of the Council of 41611 December 2013 on the Common Fisheries Policy, amending Council Regulations (EC) No 1954/2003 417 and (EC) No 1224/2009 and repealing Council Regulations (EC) No 2371/2002 and (EC) No 639/2004 and 418 Council Decision 2004/585/EC. Official Journal of the European Communities, L354: 22-61.

419 Feekings, J., Christensen, A., Jonsson, P., Frandsen, R., Ulmestrand, M., Munch-Petersen, S., and 420 Andersen, B. 2015. The use of at-sea-sampling data to dissociate environmental variability in Norway 421 lobster (Nephrops norvegicus) catches to improve resource exploitation efficiency within the 422 Skagerrak/Kattegat trawl fishery. Fish. Oceanogr. 24(4), 383-392. doi: 10.1111/fog.12116 
423 Frandsen, R.P., Herrmann, B., Madsen, N., and Krag, L.A. 2011. Development of a codend concept to 424 improve size selectivity of Nephrops (Nephrops norvegicus) in a multi-species fishery. Fish. Res. 111(1), 425 116-126. doi:10.1016/j.fishres.2011.07.003

426 Glass, C.W. 2000. Conservation of fish stocks through bycatch reduction: a review. Northeast. Nat. 7(4), 427 395-410. doi:10.1656/1092-6194(2000)007[0395:COFSTB]2.0.CO;2

428 Glass, C.W., and Wardle, C.S. 1989. Comparison of the reactions of fish to a trawl gear, at high and low 429 light intensities. Fish. Res. 7, 249-266. doi:10.1016/0165-7836(89)90059-3

430 Graham, N., and Fryer, R.J. 2006. Separation of fish from Nephrops norvegicus into a two-tier cod-end 431 using a selection grid. Fish. Res. 82(1), 111-118. doi:10.1016/j.fishres.2006.08.011

432 Grimaldo, E., Sistiaga, M., and Larsen, R.B. 2008. Evaluation of codends with sorting grids, exit windows, 433 and diamond meshes: size selection and fish behaviour. Fish. Res. 91(2), 271-280. 434 doi:10.1016/j.fishres.2007.12.003

435 Hannah, R.W. and Jones, S.A. 2001. Bycatch reduction in an ocean shrimp trawl from a simple 436 modification to the trawl footrope. J. Northw. Atl. Fish. Sci. 27, 227-233. doi:10.2960/J.v27.a19

437 Harley, S.J., and Myers, R.A. 2001. Hierarchical Bayesian models of length-specific catchability of 438 research trawl surveys. Can. J. Fish. Aquat. Sci. 58(8), 1569-1584. doi:10.1139/f01-097

439 He, P. 1993. Swimming speeds of marine fish in relation to fishing gears. In ICES Marine Science 440 Symposia 196, 183-189.

441 He, P. 2011. Behavior of marine fishes: capture processes and conservation challenges. John Wiley \& 442 Sons. 
443 He, P., Goethel, D., and Smith, T. 2007. Design and test of a topless shrimp trawl to reduce pelagic fish 444 bycatch in the Gulf of Maine pink shrimp fishery. J. Northw. Atl. Fish. Sci. 38, 13-21. doi:10.1.1.621.5508

445 Herrmann, B., Sistiaga, M.B., Nielsen, K.N., and Larsen, R.B. 2012. Understanding the size selectivity of 446 redfish (Sebastes spp.) in North Atlantic trawl codends. J. Northw. Atl. Fish. Sci. 44, 1-13. doi: $447 \quad 10.2960 / J . v 44 . m 680$

448 Herrmann, B., Sistiaga, M., Rindahl, L., and Tatone, I. 2017. Estimation of the effect of gear design 449 changes on catch efficiency: Methodology and a case study for a Spanish longline fishery targeting hake 450 (Merluccius merluccius). Fish. Res. 185, 153-160. doi:10.1016/j.fishres.2016.09.013

451 Holst, R., Ferro, R.S., Krag, L.A., Kynoch, R.J., and Madsen, N. 2009. Quantification of species selectivity 452 by using separating devices at different locations in two whitefish demersal trawls. Can. J. Fish. Aquat. 453 Sci. 66(12), 2052-2061. doi:10.1139/F09-145

454 Jones, E.G., Summerbell, K., and O'Neill, F. 2008. The influence of towing speed and fish density on the 455 behaviour of haddock in a trawl cod-end. Fish. Res. 94(2), 166-174. doi:10.1016/j.fishres.2008.06.010

456 Karlsen, J. D., Krag, L. A., Albertsen, C. M., and Frandsen, R. P. 2015. From fishing to fish processing: 457 separation of fish from crustaceans in the Norway lobster-directed multispecies trawl fishery improves 458 seafood quality. PLOS ONE 10(11), e0140864. doi:10.1371/journal.pone.0140864

459 Kelleher, K. 2005. Discards in the world's marine fisheries: an update. FAO Fisheries Technical Paper No. 460 470. Food and Agriculture Organization of the United Nations, Rome, Italy.

461 Kim, Y.H., and Wardle, C.S. 1998. Measuring the brightness contrast of fishing gear, the visual stimulus 462 for fish capture. Fish. Res. 34, 151-164. doi:10.1016/S0165-7836(97)00087-8 
463 Krag, L.A., Frandsen, R.P., and Madsen, N. 2008. Evaluation of a simple means to reduce discard in the 464 Kattegat-Skagerrak Nephrops (Nephrops norvegicus) fishery: commercial testing of different codends 465 and square-mesh panels. Fish. Res. 91, 175-186. doi:10.1016/j.fishres.2007.11.022

466 Krag, L.A., Holst, R., and Madsen, N. 2009. The vertical separation of fish in the aft end of a demersal 467 trawl. ICES J. Mar. Sci. 66(4), 772-777. doi:10.1093/icesjms/fsp034

468 Krag, L.A., Holst, R., Madsen, N., Hansen, K., and Frandsen, R.P. 2010. Selective haddock 469 (Melanogrammus aeglefinus) trawling: avoiding cod (Gadus morhua) bycatch. Fish. Res. 101, $20-26$. 470 doi:10.1016/j.fishres.2009.09.001

471 Krag, L.A., Herrmann, B., and Karlsen, J.D. 2014. Inferring fish escape behaviour in trawls based on catch 472 comparison data: model development and evaluation based on data from Skagerrak, Denmark. PLOS 473 ONE 9(2), e88819. doi:10.1371/journal.pone.0088819

474 Krag, L.A., Herrmann, B., Karlsen, J.D., and Mieske, B. 2015. Species selectivity in different sized topless 475 trawl designs: Does size matter? Fish. Res. 172, 243-249. doi:10.1016/j.fishres.2015.07.010

476 Lomeli, M.J., and Wakefield, W.W. 2013. A flexible sorting grid to reduce Pacific halibut (Hippoglossus 477 stenolepis) bycatch in the US west coast groundfish bottom trawl fishery. Fish. Res. 143, 102-108. 478 doi:10.1016/j.fishres.2013.01.017

479 Mathai, T.J., Syed Abbas, M., and Mhalathkar, H.N. 1984. Towards optimisation of bridle lengths in 480 bottom trawls. Fish. Technol. 21(2), 106-108. Available from: 481 http://aquaticcommons.org/id/eprint/18448 [accessed 12/07/2017] 
482 McHugh, M.J., Broadhurst, M.K., and Sterling, D.J. 2017. Choosing anterior-gear modifications to reduce 483 the global environmental impacts of penaeid trawls. Rev. Fish Biol. Fisher. 1-24. doi:10.1007/s11160$484 \quad 016-9459-5$

485 Noettestad, L., and Axelsen, B.E. 1999. Herring schooling manoeuvres in response to killer whale 486 attacks. Can. J. Zool. 77, 1540-1546. doi:10.1139/z99-124

487 Rose, C.S., Gauvin, J.R., and Hammond, C.F. 2010. Effective herding of flatfish by cables with minimal 488 seafloor contact. Fish. Bull. 108(2), 136-145. Available from: http://aquaticcommons.org/id/eprint/8752 489 [accessed 12/07/2017]

490 Ryer, C.H. 2008. A review of flatfish behavior relative to trawls. Fish. Res. 90,138-146. 491 doi:10.1016/j.fishres.2007.10.005

492 Ryer, C.H., and Barnett, L.A. 2006. Influence of illumination and temperature upon flatfish reactivity and 493 herding behavior: potential implications for trawl capture efficiency. Fish. Res. 81(2), 242-250. 494 doi:10.1016/j.fishres.2006.07.001

495 Sistiaga, M., Herrmann, B., Grimaldo, E., Larsen, R.B., and Tatone, I. 2015. Effect of lifting the sweeps on 496 bottom trawling catch efficiency: A study based on the Northeast arctic cod (Gadus morhua) trawl 497 fishery. Fish. Res. 167, 164-173. doi:10.1016/j.fishres.2015.01.015

498 Walsh, S. J., and Hickey, W. M. 1993. Behavioural reactions of demersal fish to bottom trawls at various 499 light conditions. In ICES Mar. Sc. 196, 68-76.

500 Wardle, C.S. 1993. Fish behaviour and fishing gear. In Pitcher, T.J. (Ed.), Behavior of Teleost Fishes, pp. 501 609-643. Champman \& Hall, London. 
502 Winger, P.D., Walsh, S.J., He, P., and Brown, J.A. 2004. Simulating trawl herding in flatfish: the role of 503 fish length in behaviour and swimming characteristics. ICES J. Mar. Sci. 61(7), 1179-1185. 504 doi:10.1016/j.icesjms.2004.07.015

505 Winger, P.D., Eayrs, S., and Glass, C.W. 2010. Fish behaviour near bottom trawls. In He, P. (Ed.), 506 Behavior of marine fishes: capture processes and conservation challenges, pp. 67-102. Wiley-Blackwell, 507 Arnes, IA.

508

509

510

511

512

513

514

515

516

517

518 


\section{List of tables}

521 Table 1: Overview of the valid hauls.

522 Table 2: Number of individuals and number of hauls per species included in the analyses.

523 Table 3: Fit statistics for the modeled catch comparison rates.

524 Table 4: Catch ratios averaged over length classes.

525

526 


\section{Table 1}

Overview of the valid hauls, showing the total catch $(\mathrm{kg})$ in the test and control trawls. Hauls were distinguished by time of the day (D=day-time, N=nighttime). The position of the test trawl was inverted every 4-6 hauls from Starboard (S) to Port (P). The total spread (Door spread) and the spread of each trawl are also reported. No data from the clump sensor were available for hauls 25 and 26.

\begin{tabular}{|c|c|c|c|c|c|c|c|c|c|c|c|c|c|}
\hline \multirow[t]{2}{*}{ Haul Nr. } & \multirow{2}{*}{$\begin{array}{l}\text { Trawl time } \\
\text { (hh:mm) }\end{array}$} & \multirow[t]{2}{*}{$\mathrm{D} / \mathrm{N}$} & \multirow{2}{*}{$\begin{array}{l}\text { Depth } \\
\text { (m) }\end{array}$} & \multirow{2}{*}{$\begin{array}{l}\text { Wind } \\
(\mathrm{m} / \mathrm{s})\end{array}$} & \multirow[t]{2}{*}{$\begin{array}{l}\text { Test } \\
\text { trawl }\end{array}$} & \multicolumn{2}{|c|}{$\begin{array}{l}\text { Doors spread } \\
(\mathrm{m})\end{array}$} & \multicolumn{2}{|c|}{$\begin{array}{l}\text { Test trawl } \\
\text { spread (m) }\end{array}$} & \multicolumn{2}{|c|}{$\begin{array}{l}\text { Control trawl } \\
\text { spread }(\mathrm{m})\end{array}$} & \multirow{2}{*}{$\begin{array}{l}\text { Tot. Catch } \\
\text { (Kg) Test }\end{array}$} & \multirow{2}{*}{$\begin{array}{l}\text { Tot. Catch } \\
\text { (Kg) Control }\end{array}$} \\
\hline & & & & & & Mean & Sd & Mean & Sd & Mean & Sd & & \\
\hline 1 & 00:50 & $\mathrm{N}$ & 33 & 5 & $\mathrm{~S}$ & 81.09 & 1.09 & 39.94 & 0.83 & 41.14 & 0.38 & 425 & 658 \\
\hline 2 & 01:00 & D & 86 & 3 & $S$ & 90.71 & 2.29 & 43.57 & 1.99 & 47.14 & 1.07 & 255 & 605 \\
\hline 3 & 01:05 & D & 87 & 3 & S & 94.75 & 2.76 & 46.25 & 1.28 & 48.50 & 1.93 & 294 & 732 \\
\hline 4 & 01:00 & D & 78 & 3 & $\mathrm{~S}$ & 94.64 & 2.93 & 46.79 & 1.62 & 47.85 & 1.57 & 1101 & 1539 \\
\hline 5 & $00: 50$ & $\mathrm{D}$ & 85 & 8 & $P$ & 95.00 & 3.39 & 47.20 & 1.48 & 47.80 & 1.92 & 491 & 833 \\
\hline 6 & $00: 40$ & D & 87 & 9 & $P$ & 91.23 & 2.98 & 45.58 & 1.26 & 45.65 & 1.81 & 381 & 538 \\
\hline 7 & $00: 45$ & D & 84 & 9 & $\mathrm{P}$ & 96.30 & 3.87 & 47.04 & 1.46 & 49.26 & 2.65 & 402 & 603 \\
\hline 8 & 02:15 & D & 61 & 8 & $\mathrm{P}$ & 83.44 & 3.01 & 41.29 & 1.16 & 42.15 & 1.99 & 102 & 199 \\
\hline 9 & 01:00 & $\mathrm{N}$ & 90 & 3 & $P$ & 93.06 & 3.62 & 46.79 & 1.85 & 46.27 & 1.92 & 199 & 410 \\
\hline 10 & 01:35 & $\mathrm{N}$ & 78 & 3 & $\mathrm{P}$ & 94.98 & 3.49 & 45.94 & 1.77 & 49.05 & 1.96 & 425 & 508 \\
\hline 11 & $00: 30$ & $\mathrm{~N}$ & 85 & 3 & $S$ & 83.13 & 3.07 & 42.30 & 0.78 & 40.83 & 3.36 & 244 & 466 \\
\hline 12 & 00:50 & D & 84 & 3 & $\mathrm{~S}$ & 81.03 & 2.31 & 41.07 & 0.84 & 39.97 & 1.57 & 1145 & 1299 \\
\hline 13 & $00: 30$ & $\mathrm{~N}$ & 77 & 3 & $S$ & 80.50 & 3.63 & 40.05 & 1.58 & 40.45 & 2.39 & 296 & 408 \\
\hline 14 & $00: 45$ & D & 80 & 2 & $S$ & 83.62 & 3.10 & 41.97 & 2.35 & 41.65 & 1.25 & 275 & 394 \\
\hline 15 & $00: 45$ & D & 84 & 2 & S & 74.33 & 1.14 & 36.92 & 0.52 & 37.42 & 0.95 & 402 & 680 \\
\hline 16 & 01:30 & D & 54 & 2 & $P$ & 88.12 & 2.04 & 43.50 & 1.23 & 44.62 & 1.05 & 130 & 171 \\
\hline 17 & 01:30 & D & 46 & 1 & $P$ & 87.81 & 3.72 & 42.71 & 1.89 & 45.10 & 2.10 & 228 & 223.5 \\
\hline 18 & 01:00 & D & 45 & 0 & $P$ & 87.47 & 1.88 & 42.11 & 1.12 & 45.36 & 0.98 & 55 & 90.5 \\
\hline 19 & 01:00 & D & 48 & 0 & P & 85.19 & 0.86 & 41.29 & 0.71 & 43.90 & 1.42 & 69 & 105 \\
\hline 20 & $00: 47$ & D & 77 & 5 & $P$ & 86.77 & 3.56 & 42.72 & 3.24 & 43.92 & 1.08 & 350 & 590 \\
\hline 21 & $00: 45$ & D & 86 & 6 & $P$ & 86.70 & 3.22 & 43.17 & 1.57 & 43.53 & 2.05 & 435 & 615 \\
\hline 22 & $00: 46$ & D & 85 & 7 & $S$ & 88.93 & 3.83 & 43.85 & 1.86 & 45.08 & 2.08 & 267 & 480 \\
\hline 23 & $00: 45$ & $\mathrm{~N}$ & 85 & 7 & S & 79.78 & 3.27 & 39.58 & 1.20 & 40.20 & 2.13 & 311 & 449 \\
\hline 24 & $00: 45$ & $\mathrm{~N}$ & 86 & 6 & $S$ & 76.70 & 3.77 & 38.00 & 1.38 & 38.70 & 2.51 & 207 & 132 \\
\hline 25 & $00: 30$ & $\mathrm{D}$ & 85 & 6 & $S$ & 80.65 & 0.45 & - & - & - & - & 247 & 388 \\
\hline 26 & $00: 46$ & $\mathrm{~N}$ & 85 & 4 & $S$ & 78.50 & 5.07 & - & - & - & - & 292 & 278 \\
\hline
\end{tabular}


532

533

534

535

536

537

538

539

540

541

542

543

544

545

546

Table 2

Number of individuals and number of hauls per species included in the analyses, for the three analyses performed. Species that were subsampled are indicated with the actual number of individuals measured (in brackets) and the raised total number (see Appendix 1).

\begin{tabular}{|ccccccc|}
\hline & \multicolumn{2}{c}{ Pooled } & \multicolumn{2}{c}{ Night-time } & \multicolumn{2}{c|}{ Day-time } \\
& Hauls & Nr & Hauls & Nr & Hauls & Nr \\
\hline \hline Nephrops & 6 & $10618(6266)$ & 1 & 21 & 5 & $10597(6245)$ \\
Cod & 23 & 6749 & 7 & 1928 & 16 & 4821 \\
Haddock & 20 & 9865 & 7 & 2242 & 13 & 7623 \\
Whiting & 26 & $28567(23341)$ & 8 & 5479 & 18 & $23088(17862)$ \\
Hake & 5 & 178 & - & - & 5 & 178 \\
Lemon sole & 19 & 2474 & 6 & 345 & 13 & 2129 \\
Plaice & 23 & $15676(13867)$ & 8 & 1725 & 15 & $13951(12142)$ \\
\hline
\end{tabular}

\section{Table 3}

Fit statistics for the modeled catch comparison rates. DoF denotes degree of freedom and is calculated by subtracting the number of model parameters from the number of length classes in the dataset analyzed.

\begin{tabular}{|cccccccccc|}
\hline & $\boldsymbol{p}$-value & $\begin{array}{c}\text { Pooled } \\
\text { Deviance }\end{array}$ & DoF & $\boldsymbol{p}$-value & $\begin{array}{c}\text { Day-time } \\
\text { Deviance }\end{array}$ & DoF & $\boldsymbol{p}$-value & $\begin{array}{c}\text { Night-time } \\
\text { Deviance }\end{array}$ & DoF \\
\hline \hline Nephrops & 0.06 & 53.74 & 39 & - & - & - & - & - & - \\
Cod & 0.03 & 100.75 & 76 & 0.02 & 101.25 & 74 & 0.31 & 64.99 & 60 \\
Haddock & 0.01 & 61.50 & 39 & $<0.01$ & 67.60 & 37 & 0.72 & 28.86 & 34 \\
Whiting & 0.01 & 51.08 & 31 & $<0.01$ & 56.74 & 31 & 0.19 & 33.15 & 27 \\
Hake & 0.21 & 52.32 & 45 & - & - & - & - & - & - \\
Plaice & 0.07 & 44.87 & 32 & 0.09 & 41.07 & 30 & 0.23 & 30.95 & 26 \\
Lemon sole & 0.42 & 22.70 & 22 & 0.69 & 18.22 & 22 & 0.03 & 28.48 & 16 \\
\hline
\end{tabular}

\section{Table 4}

Catch ratios averaged over length classes with $95 \%$ confidence intervals. The percentages for the total catch of the fish species analyzed, both below and above the MCRS, and the percentages per species are reported. The baseline for no effect of FLEXSELECT is 0.98 . Percentages in the text are obtained by subtracting the catch ratio from 0.98 and multiplying the difference by 100 .

\begin{tabular}{|cccc|}
\hline & Mean & Cl Low & Cl High \\
\hline \hline Tot fish & 0.59 & 0.52 & 0.69 \\
Fish<MCRS & 0.69 & 0.59 & 0.79 \\
Fish>MCRS & 0.49 & 0.41 & 0.59 \\
\hline \hline Cod & 0.96 & 0.85 & 1.13 \\
Haddock & 0.41 & 0.30 & 0.54 \\
Whiting & 0.52 & 0.45 & 0.61 \\
Hake & 0.35 & 0.22 & 0.49 \\
Plaice & 0.79 & 0.64 & 0.89 \\
Lemon sole & 0.33 & 0.28 & 0.41 \\
\hline
\end{tabular}




\section{Figures captions}

548

549

550

551

552

553

554

555

556

557

558

559

560

561

562

563

564

565

566

567

568

Figure 1: FLEXSELECT design.

Figure 1. A) The port trawl in a twin-rig with FLEXSELECT mounted. Proportions are not respected to facilitate the identification of all FLEXSELECT components. B) Desired counter-herding effect. The grey arrows represent the direction of fish escape.

Figure 2: Catch comparison rates and catch ratios for the target species Nephrops.

Figure 2. Catch comparison rates and catch ratios for Nephrops. On the left: the curve (solid line) represents the modeled catch efficiency fitted to the experimental points (dots). The grey band represents $95 \%$ confidence intervals and the dashed line the length distribution observed in the catch. The dotted horizontal line, located at 0.49 , describes equivalence in catch rates between the two trawls. On the right: catch ratio curve (solid line) with $95 \%$ confidence intervals (grey band). The dotted horizontal line, located at 0.98 , describes equivalence in catch rates between the two trawls.

Figure 3: Catch comparison rates and catch ratios for the four roundfish species.

Figure 3. Catch comparison rates and catch ratios for the four roundfish species. On the left: catch comparison curves (solid lines) representing the modeled catch efficiencies fitted to the experimental points (dots). The grey bands show 95\% confidence intervals and the dashed lines the length distributions observed in the catch. The dotted horizontal lines, located at 0.49 , represent the baseline for no effect. On the right: catch ratio curves (solid line) with $95 \%$ confidence intervals (grey bands). The dotted horizontal lines, located at 0.98 , describe equivalence in catch between the two trawls. 
569 Figure 4: Catch comparison rates and catch ratios for the two flatfish species.

570 Figure 4. Catch comparison rates and catch ratios for the two flatfish species. On the left: catch comparison curves

571 (solid lines) representing the modeled catch efficiencies fitted to the experimental points (dots). The grey bands show

$57295 \%$ confidence intervals and the dashed lines the length distributions observed in the catch. The dotted horizontal

573 lines, located at 0.49 , represent the baseline for no effect. On the right: catch ratio curves (solid line) with $95 \%$

574 confidence intervals (grey bands). The dotted horizontal lines, located at 0.98 , describe equivalence in catch between

575 the two trawls.

576

577 Figure 5: Catch comparison curves for day-time hauls, night-time hauls and overlap comparison.

578 Figure 5. Catch comparison curves for day-time hauls $\left(1^{\text {st }}\right.$ column), night-time hauls $\left(2^{\text {nd }}\right.$ column) and overlap 579 comparison ( $3^{\text {rd }}$ column). The experimental points (dots) and catch distribution (dashed lines) per each group of hauls 580 is reported. The modelled fits for day-time (bold full lines) and night-time (bold dashed lines) are shown with the 581 respective $95 \%$ confidence intervals (grey bands). The bands borders are dashed for night-time confidence intervals.

582 The dotted horizontal lines, at 0.49 , describe equivalence in catch rates between the two trawls. 


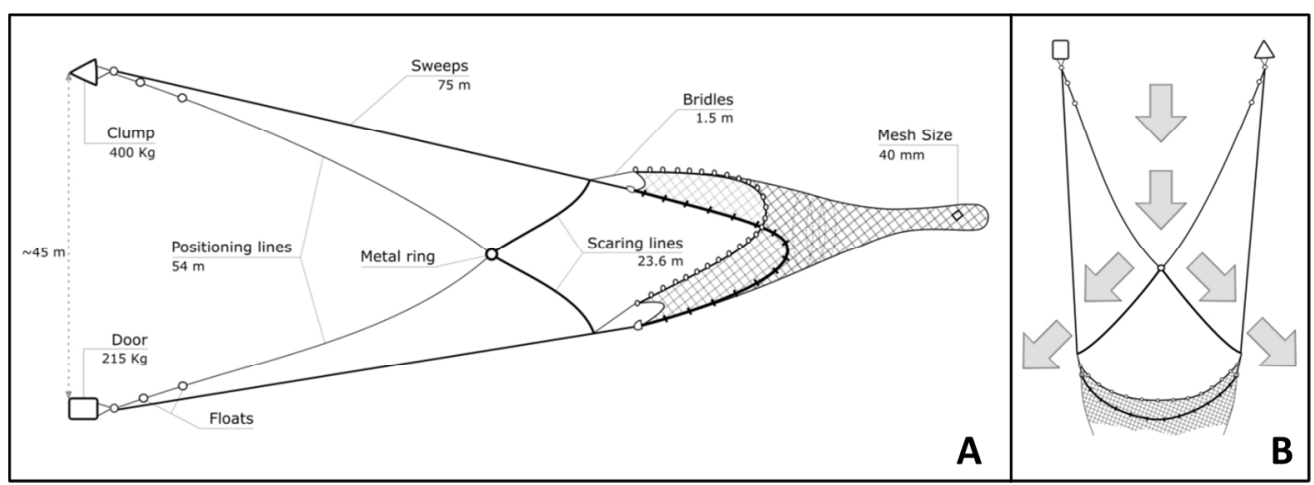

Figure 1. A) The port trawl in a twin-rig with FLEXSELECT mounted. Proportions are not respected to facilitate the identification of all FLEXSELECT components. B) Desired counter-herding effect. The grey arrows represent the direction of fish escape.

$174 \times 62 \mathrm{~mm}(300 \times 300 \mathrm{DPI})$ 


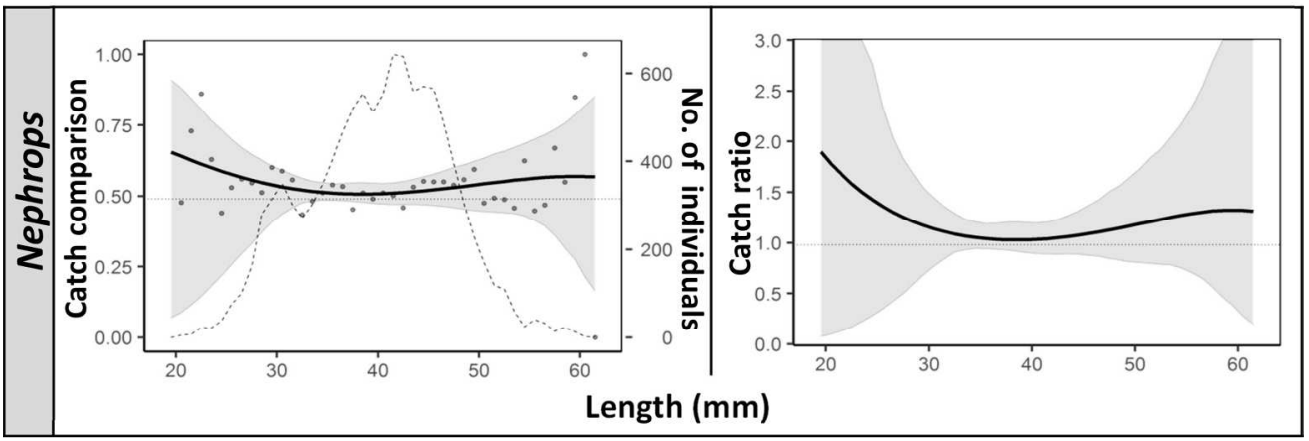

Figure 2. Catch comparison rates and catch ratios for Nephrops. On the left: the curve (solid line) represents the modeled catch efficiency fitted to the experimental points (dots). The grey band represents $95 \%$ confidence intervals and the dashed line the length distribution observed in the catch. The dotted horizontal line, located at 0.49 , describes equivalence in catch rates between the two trawls. On the right: catch ratio curve (solid line) with $95 \%$ confidence intervals (grey band). The dotted horizontal line, located at 0.98 , describes equivalence in catch rates between the two trawls.

$182 \times 61 \mathrm{~mm}(300 \times 300 \mathrm{DPI})$ 


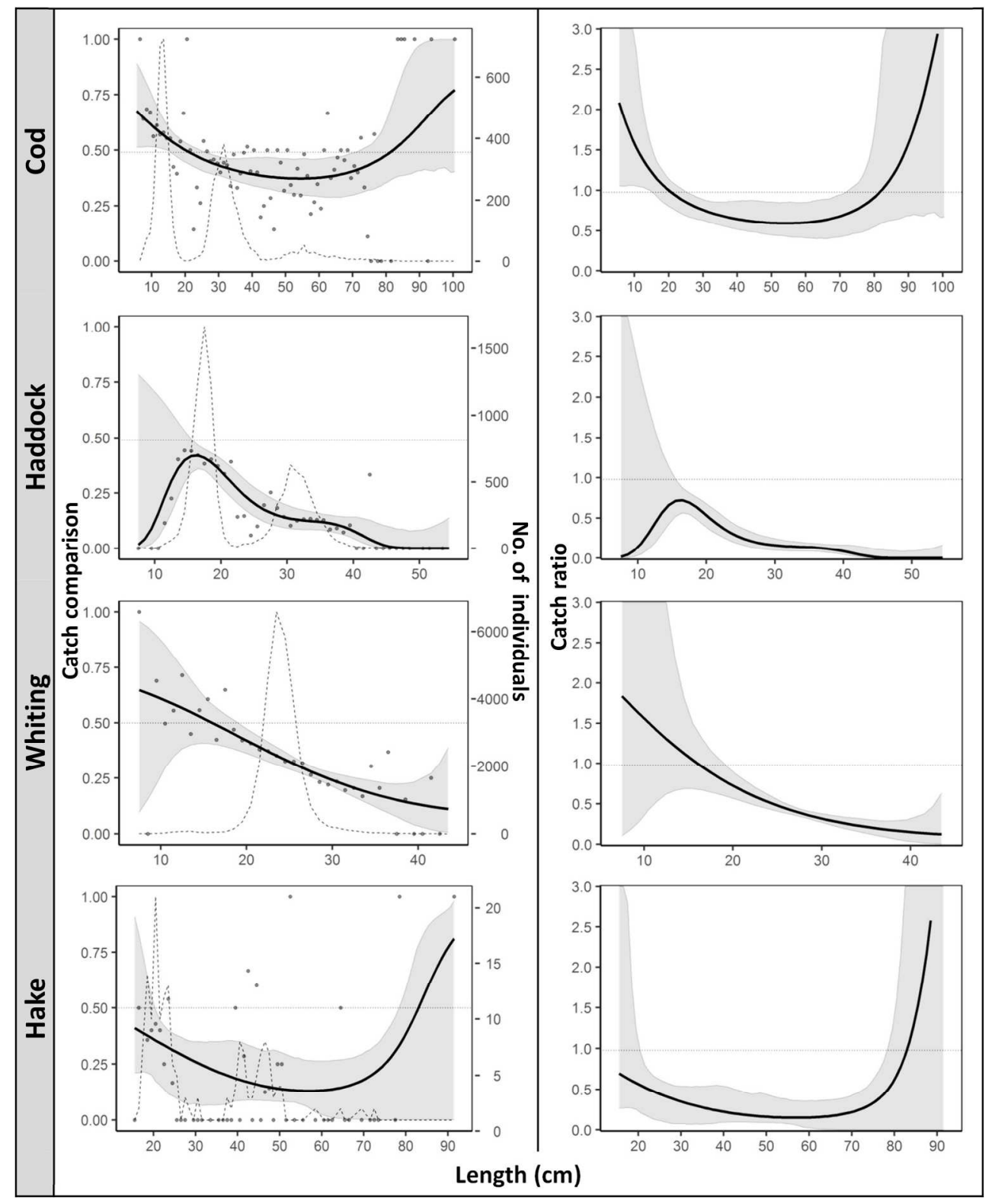

Figure 3. Catch comparison rates and catch ratios for the four roundfish species. On the left: catch comparison curves (solid lines) representing the modeled catch efficiencies fitted to the experimental points (dots). The grey bands show 95\% confidence intervals and the dashed lines the length distributions observed in the catch. The dotted horizontal lines, located at 0.49 , represent the baseline for no effect. On the right: catch ratio curves (solid line) with 95\% confidence intervals (grey bands). The dotted horizontal lines, located at 0.98 , describe equivalence in catch between the two trawls.

$184 \times 226 \mathrm{~mm}(300 \times 300$ DPI $)$ 


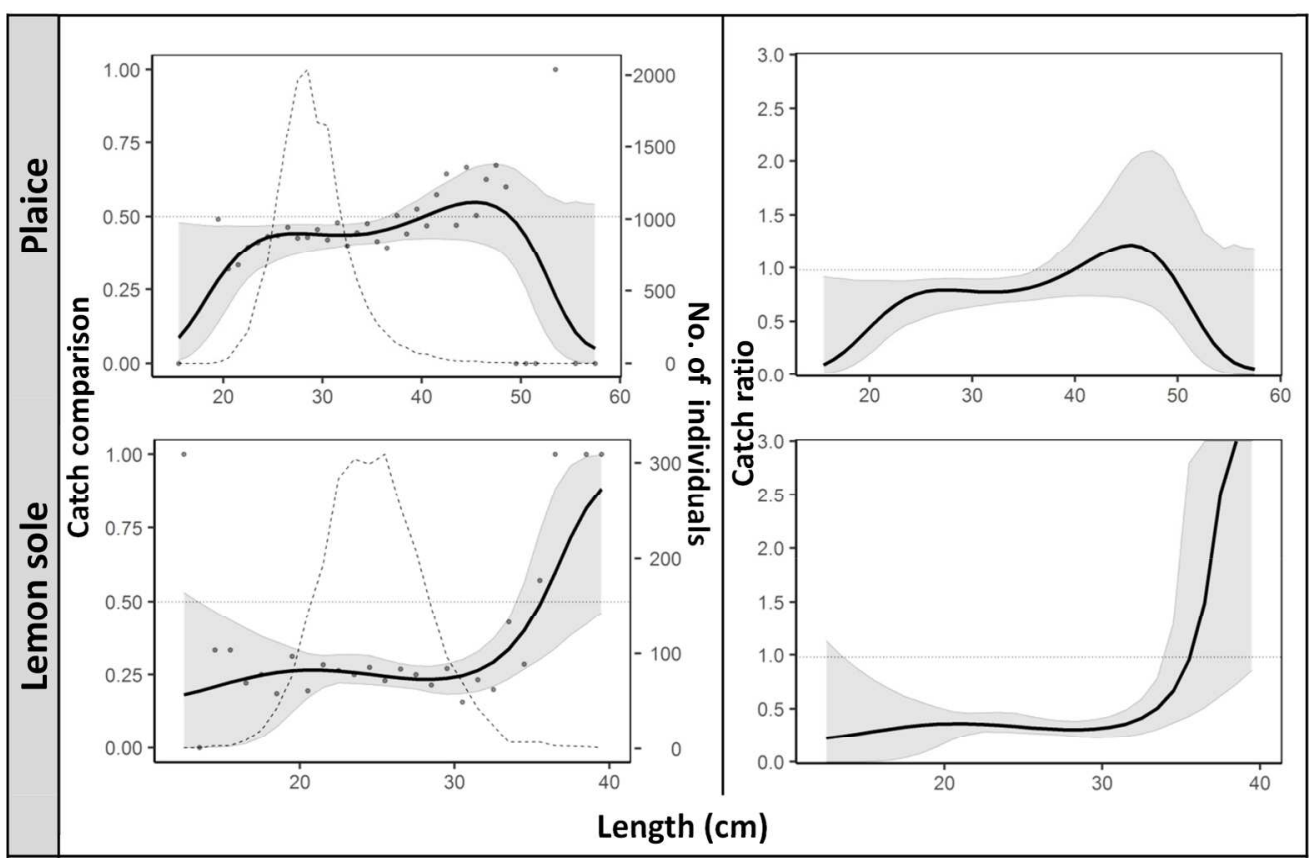

Figure 4. Catch comparison rates and catch ratios for the two flatfish species. On the left: catch comparison curves (solid lines) representing the modeled catch efficiencies fitted to the experimental points (dots). The grey bands show 95\% confidence intervals and the dashed lines the length distributions observed in the catch. The dotted horizontal lines, located at 0.49, represent the baseline for no effect. On the right: catch ratio curves (solid line) with $95 \%$ confidence intervals (grey bands). The dotted horizontal lines, located at 0.98 , describe equivalence in catch between the two trawls.

$182 \times 118 \mathrm{~mm}(300 \times 300 \mathrm{DPI})$ 


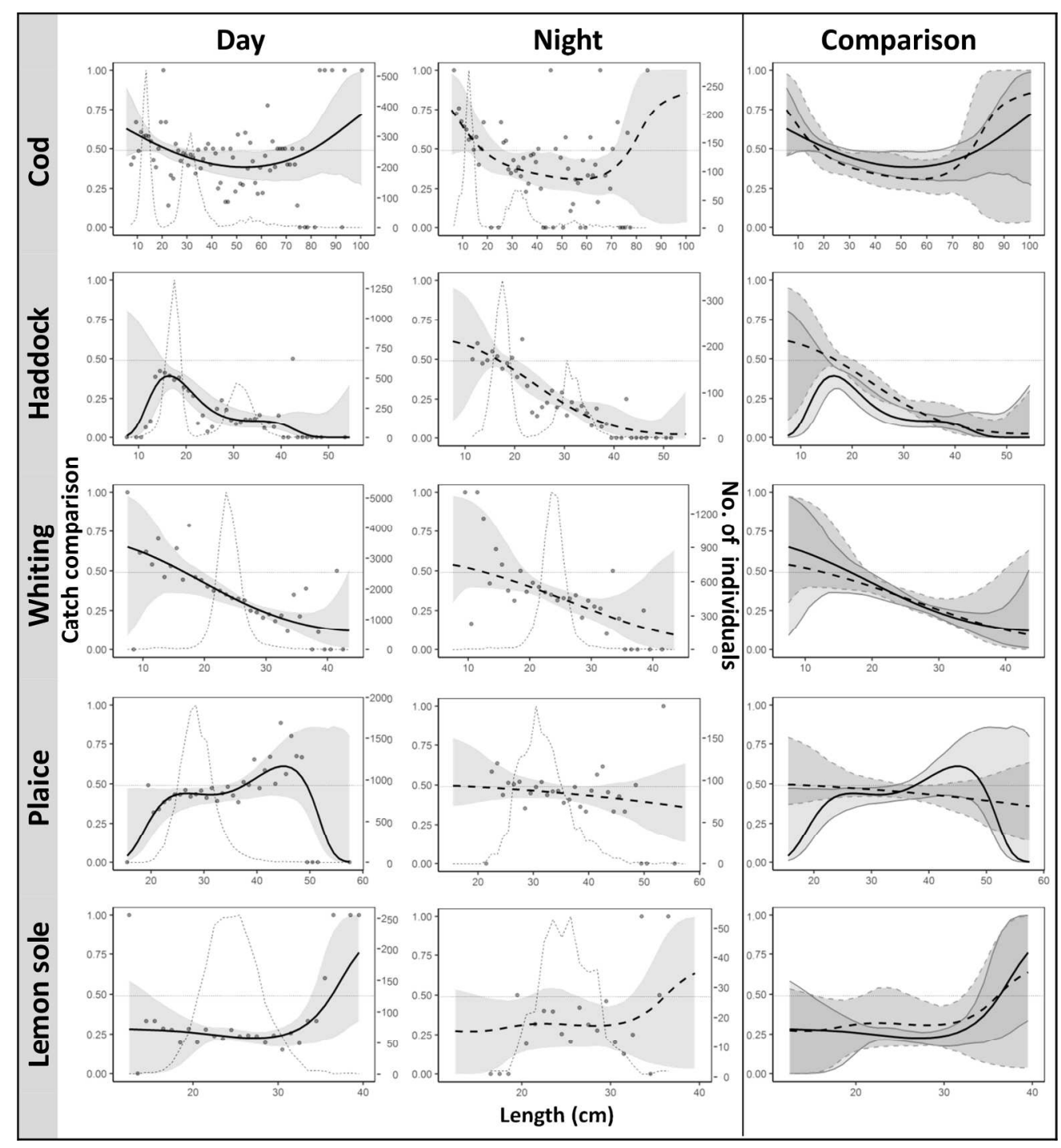

Figure 5. Catch comparison curves for day-time hauls (1st column), night-time hauls (2nd column) and overlap comparison (3rd column). The experimental points (dots) and catch distribution (dashed lines) per each group of hauls is reported. The modelled fits for day-time (bold full lines) and night-time (bold dashed lines) are shown with the respective 95\% confidence intervals (grey bands). The bands borders are dashed for night-time confidence intervals. The dotted horizontal lines, at 0.49 , describe equivalence in catch rates between the two trawls.

$188 \times 204 \mathrm{~mm}(300 \times 300 \mathrm{DPI})$ 


\section{Appendix 1}

2 Estimation of the catch comparison curve

3 The effect of FLEXSELECT was assessed for each species separately based on comparing the

4 catch in the test trawl (T) with the catch in the control trawl (C) while accounting for a

5 potential length dependent effect. Due to a second experiment, not included in the present

6 study, each trawl was divided into an upper (U) and lower (D) codend. Consequently, the

7 number of individuals $n$ of length class I being measured in a trawl haul $j$ consisted of four

8 numbers (counts) $n T U_{l j}, n T D_{l j}, n C U_{l j}$ and $n C D_{l j}$. Each compartment had an associated species-

9 specific sampling factor $q T U_{l j}, q T D_{l j}, q C U_{l j}$ and $q C D_{l j}$, generally equal to 1.0, except for a few

10 hauls where catches of Nephrops, plaice and whiting were subsampled.

11 For each species, the experimental catch comparison rate $c c_{\text {I }}$ for length / was given by:

12

$$
c c_{l}=\frac{\sum_{j=1}^{h}\left(\frac{n T U_{l j}}{q T U_{j}}+\frac{n T D_{l j}}{q T D_{j}}\right)}{\sum_{j=1}^{h}\left(\frac{n T U_{l j}}{q T U_{j}}+\frac{n T D_{l j}}{q T D_{j}}+\frac{n C U_{l j}}{q C U_{j}}+\frac{n C D_{l j}}{q C D_{j}}\right)}
$$

13 where the summation is over hauls $h$.

14 The length-dependent count data of each species were used to estimate a model for size dependent catch comparison rate $c c(/)$ averaged over hauls using maximum likelihood estimation by minimizing the following equation:

17 (2) $g(\boldsymbol{v})=-\sum_{l} \sum_{j=1}^{h}\left\{\left(\frac{n T U_{l j}}{q T U_{j}}+\frac{n T D_{l j}}{q T D_{j}}\right) \times \ln (c c(l, \boldsymbol{v}))+\left(\frac{n C U_{l j}}{q C U_{j}}+\frac{n C D_{l j}}{q C D_{j}}\right) \times \ln (1-c c(l, \boldsymbol{v}))\right\}$

18 where $\boldsymbol{v}$ represents the parameters describing the catch comparison curve $c c(l, v)$. 
19 A fundamental step is to find a model for $c c(l, v)$ sufficiently flexible to account for the curvature for all the different species and considering potential differences between day and night hauls. We adapted a flexible model for $c c(l, \boldsymbol{v})$ often applied for catch comparison studies (Krag et al., 2014, 2015):

$$
c c(l, \boldsymbol{v})=\frac{\exp (f(l, v))}{1.0+\exp (f(l, v))}
$$

where $f$ is a polynomial of order $k$ with coefficients $v_{0}, \ldots, v_{k}$ so $\boldsymbol{v}=\left(v_{0}, \ldots, v_{k}\right)$. We used $f(l, v)$ of the following form:

(4) $f(l, v)=\sum_{i=0}^{4} v_{i} \times\left(\frac{l}{100}\right)^{i}=v_{0}+v_{1} \times \frac{l}{100}+v_{2} \times \frac{l^{2}}{100^{2}}+\cdots+v_{4} \times \frac{l^{4}}{100^{4}}$

Leaving out one or more of the parameters $v_{0} \ldots v_{4}$ in equation (4) provided 31 additional models that were considered as potential models to describe $c c(l, v)$. Model averaging, ranking the models according to how likely they were compared to each other (Burnham and Anderson, 2002), was then applied to describe $c c(l, v)$. To obtain a combined model, the individual models were ranked and weighted according to their Akaike's Information Criterion (AIC) values (Akaike 1974; Burnham and Anderson 2002; Herrmann et al. 2017). Models with AIC values within +10 the value of the model with the lowest AIC, were considered to contribute to $c c(l, v)$ (Katsanevakis 2006; Herrmann et al. 2017). One advantage of using this combined model approach is that we avoid having to choose one specific model among the different candidates. The ability of the combined model to describe the experimental data was assessed based on the $p$-value, which expresses the likelihood for obtaining at least as large a discrepancy as that observed between the fitted model and the experimental data, by coincidence. Therefore, for the combined model to be 
41 poor fit statistics ( $p$-value $<0.05$; deviance $>>$ degrees of freedom), the deviations between

42 the experimental observed points and the fitted curve were examined to determine

43 whether this was caused by structural problems in describing the experimental data or due

44 to data overdispersion.

45 Confidence intervals $(\mathrm{Cl})$ for the size-dependent effect of FLEXSELECT were estimated using

46 a double bootstrap method (Millar 1993). The procedure accounted for uncertainty due to

47 between-haul variation by selecting $h$ hauls with replacement from the $h$ hauls available

48 during each bootstrap repetition. Within-haul uncertainty in the size structure of the catch

49 data was accounted for by randomly selecting individuals with replacement from each of

50 the selected hauls separately from the four codends. The number of individuals selected

51 from each haul was the number of individuals length measured in that haul in each of the

52 codends, respectively. One thousand bootstrap repetitions were performed, and the Efron

$5395 \% \mathrm{Cl}$ (Efron 1982) was calculated for the catch comparison curve. Incorporating this

54 combined model approach in each of the bootstrap repetitions enabled us to account for

55 additional uncertainty in the catch comparison curve due to model averaging (Herrmann et

56 al. 2017).

57 The baseline for no effect of FLEXSELECT on the catch comparison rate is a value of 0.5 for

58 paired catch comparison data (Krag et al. 2014). However, this assumed that the two trawls

59 fish an area of similar size. Therefore, an additional baseline $c c_{0}$ that accounts for potential

60 differences due to differences in door to clump distance is also applied:

61

(5) $\quad c c_{0}=\frac{\sum_{j=1}^{h} S T_{j}}{\sum_{j=1}^{h}\left(S T_{j}+S C_{j}\right)}$ 
62 where $S T_{j}$ and $S C_{j}$ are respectively the averaged door to clump distance for the test and control trawl in haul $j$.

\section{Estimation of the catch ratio curve}

65 The catch comparison rate $c c(l, v)$ cannot be used to quantify directly the effect of FLEXSELECT on an individual of length $I$. Instead, we used the catch ratio $\mathrm{cr}(I, \boldsymbol{v})$, that gives a

67 direct relative value of the catch efficiency between the test and control trawl. For the experimental data, the catch ratio for a length class / is expressed as follows:

69

$$
c r_{l}=\frac{\sum_{j=1}^{h}\left(\frac{n T U_{l j}}{q T U_{j}}+\frac{n T D_{l j}}{q T D_{j}}\right)}{\sum_{j=1}^{h}\left(\frac{n C U_{l j}}{q C U_{j}}+\frac{n C D_{l j}}{q C D_{j}}\right)}
$$

70 Simple mathematical manipulation based on (1) and (6) yields the following general relationship between the catch ratio and the catch comparison:

$$
c r_{l}=\frac{c c_{l}}{1-c c_{l}}
$$

which also means that the same relationship exists for the functional forms:

$$
\operatorname{cr}(l, \boldsymbol{v})=\frac{c c(l, \boldsymbol{v})}{1-c c(l, v)}
$$

One advantage of using the catch ratio in the way it is defined by (6) and (8) is that if the catch efficiency of both trawls is equal, i.e. no effect of the FLEXSELECT device, the $\operatorname{cr}(l, v)$ would be 1.0. $A \operatorname{cr}(l, v)=1.25$ would mean that the test trawl catches on average $25 \%$ more fish or Nephrops with length / than the control trawl. In contrast, $\operatorname{ar}(I, v)=0.75$ would mean that the test trawl catches $25 \%$ less fish of length / than the control trawl. Similar to the process for the catch comparison rate, we corrected the baseline for no effect of 
81 FLEXSELECT by accounting for differences in the area fished between test and control trawl

82 (9) (i.e. differences in door to clump distance):

83

(9) $\quad c r_{0}=\frac{\sum_{j=1}^{h} S T_{j}}{\sum_{j=1}^{h} S C_{j}}$

84 Using equation (8) and incorporating the calculation of $c r(l, v)$ for each relevant length class

85 into the double bootstrap procedure describedabove, we estimated the confidence limits 86 for the catch ratio.

\section{Estimation of length-integrated catch ratio}

88 A length-integrated average value for the catch ratio can be estimated by:

89

$$
c r_{\text {average }}=\frac{\sum_{l} \sum_{j=1}^{h}\left(\frac{n T U_{l j}}{q T U_{j}}+\frac{n T D_{l j}}{q T D_{j}}\right)}{\sum_{l} \sum_{j=1}^{h}\left(\frac{n C U_{l j}}{q C U_{j}}+\frac{n C D_{l j}}{q C D_{j}}\right)}
$$

where the outer summation covers the length classes in the catch during the experimental fishing period. By incorporating $c r_{\text {average }}$ into each of the bootstrap iterations described above, we were able to assess the $95 \%$ confidence limits for $c r_{\text {average. }}$ We used $c r_{\text {average }}$ to provide length-averaged values for the effect of FLEXSELECT on the catch efficiency. In contrast to the length-dependent evaluation of the catch ratio, $c r_{\text {average }}$ values are specific for the population structure encountered during the experimental trial. Therefore, these values are specific for the size structure at the time the trial was carried out, and cannot be extrapolated to other scenarios in which the size structure of the fish population may be different. 
References

Akaike, H. 1974. A new look at the statistical model identification. IEEE T. Automat. Contr. 19, 716-

Burnham, K.P., Anderson, D.R. 2002. Model Selection and Multimodel Inference: A Practical Information-theoretic Approach, 2nd ed. Springer, New York.

Efron, B. 1982. The jackknife, the bootstrap and other resampling plans. In Society for industrial and applied mathematics (SIAM) Monograph No. 38, CBSM-NSF. changes on catch efficiency: Methodology and a case study for a Spanish longline fishery targeting hake (Merluccius merluccius). Fish. Res. 185, 153-160. doi:10.1016/j.fishres.2016.09.013

Katsanevakis, S. 2006. Modeling fish growth: Model selection, multi-model inference and model selection uncertainty. Fish. Res. 81, 229-235. doi:10.1016/j.fishres.2006.07.002

Krag, L.A., Herrmann, B., and Karlsen, J. 2014. Inferring fish escape behaviour in trawls based on catch comparison data: Model development and evaluation based on data from Skagerrak, Denmark. PLOS ONE 9(2): e88819. doi:10.1371/journal.pone.0088819.

Krag, L.A., Herrmann, B., Karlsen, J.D., and Mieske, B. 2015. Species selectivity in different sized topless trawl designs: Does size matter? Fish. Res. 172, 243-249. doi:10.1016/j.fishres.2015.07.010

Millar, R.B. 1993. Incorporation of between-haul variation using bootstrapping and nonparametric estimation of selection curves. Fish. Bullet. 91, 564-572. 